\title{
Understanding students as hosts: moving beyond sightseeing
}

Tanja Petry, Birgit Pikkemaat, Chung-Shing Chan and Ursula Scholl-Grissemann

\begin{abstract}
Purpose - Neither visitors of visiting friends and relatives (VFR) travel nor hosts are homogeneous segments (Griffin \& Guttenberg, 2020). For this reason, this study aims to address students as hosts of VFR travel and analyzes differences in the visitor and the host segment. As a result, marketing implications for destination marketing organizations that seek to realize the potential of the student VFR segment arise.
\end{abstract}

Design/methodology/approach - This research project adopts a multi-method approach to derive a deeper empirical understanding of visitors' behaviors and the role of students hosting friends and relatives (SHFR). The quantitative study aims to reveal the relevance and differences between visits to friends (VF) and visits to relatives (VR), whereas the qualitative study elaborates on the findings of the quantitative study and seeks to understand the role and experiences of students as hosts.

Findings - The findings reveal that VR and VF travelers vary in terms of their expenditure. Hosts' spending depends on visitors' budgets; in general, both their direct and indirect (when relatives pay) spending increases when they have visitors. Furthermore, the data identify two distinct hosting styles: functional hosting is concerned with providing outstanding hospitality based on a more traditional, guestoriented understanding of the role, whereas integrative hosting blurs the lines between hospitality and lifestyle based on a more modern, host-oriented understanding of the role.

Research limitations/implications - Regarding limitations, this study did not differentiate between students who were simultaneously locals and students who resided in the city only for study purposes. In a similar vein, the cultural background of the students was not considered in the research. Finally, the differences between VF and VR could further be explored in a quantitative follow-up study and in testing for significant differences in SHFR spending behaviors. Further research could examine whether domestic travelers, travelers with cultural proximity and/or short-distance VFR travelers are more likely to visit after COVID-19 as suggested by Backer and Ritchie (2017) in the case of crises and disaster.

Practical implications - Students as hosts differ from other hosts in VFR travel in their reluctance to embrace conventional tourism products. This study found that place attachment makes hosts of VFR travelers passionate ambassadors and advertisers for the destinations; destination marketing organizations (DMOs) could support this already positive image by providing and supporting students with more detailed information about their cities and the opportunities they offer. Results are of particular relevance because the COVID-19 pandemic is forcing DMOs to develop destination strategies that incorporate social-distancing and avoid crowded places.

Social implications - When students take their friends out to events and nightclubs, they contribute significantly to experiences that go beyond typical tourism activities such as sightseeing and shopping. By offering special discounts to visitors who come with their hosts, DMOs could help visitors delve more deeply into city life and thereby reduce the likeliness of crowded city centers. Considering the findings relating to the social and emotional qualities of VFR travel, DMO marketing to VFR travelers could benefit from promoting socio-cultural spaces and offerings that value groups' social ties (e.g. family prices for families with adult children) or alumni status.

Originality/value - According to the authors' knowledge, this study is the first which analyzes both, visitors and hosts of VFR travel using a two methods approach. Very recently, Griffin and Guttenberg (2020) miss VFR research focusing on the heterogeneity of the segment, and Backer et al. (2020) claim for more VFR research on the role of hosts carried out outside of Australia, New Zealand, Canada, the UK
Tanja Petry and

Birgit Pikkemaat both are based at the Institute for Strategic Management, Marketing and Tourism, University of Innsbruck, Innsbruck, Austria. ChungShing Chan is based at the Department of Geography and Resource

Management, The Chinese University of Hong Kong, Hong Kong, China.

Ursula Scholl-Grissemann is based at the Institute for Management and Economics in Health Care, UMIT - University for Health Sciences, Medical Informatics and Technology, Hall in Tirol, Austria.

Received 20 September 2020 Revised 3 December 2020 16 February 2021 22 February 2021

Accepted 4 March 2021

() Tanja Petry, Birgit Pikkemaat, Chung-Shing Chan and Ursula Scholl-Grissemann. Published by Emerald Publishing Limited. This article is published under the Creative Commons Attribution (CC BY 4.0) licence. Anyone may reproduce, distribute, translate and create derivative works of this article (for both commercial and non-commercial purposes), subject to full attribution to the original publication and authors. The full terms of this licence may be seen at http://creativecommons.org/licences/by/4.0/ 
and the USA. To the authors' best knowledge, this study is the first which delivers empirical insights on SHFR in Central Europe.

Keywords Visiting friends versus visiting relatives, Students, Hosting style, Place attachment,

Destination marketing

Paper type Research paper

\section{Introduction}

In the past decade, visiting friends and relatives (VFR) travel has been given considerable attention by tourism researchers (Griffin and Guttentag, 2020; Backer et al., 2020; Backer, 2019; Zhao et al., 2019; Choi and Fu, 2018; Backer et al., 2017). Importantly, VFR travel is not a homogenous market; it consists of two subsegments of visits to friends (VF) and visits to relatives (VR); the profiles and characteristics of these two segments have not yet been defined in sufficient detail. This lacking distinction impedes effective tourism marketing initiatives, suggesting the need for tailored marketing campaigns and products that target both segments (Backer et al., 2017). Griffin and Guttentag (2020) highlight that both visitors and hosts are not homogenous, and that an additional understanding of different hosting experiences is beneficial.

Tourism organizations increasingly consider the expectations and vacation lifestyles of younger generations of travelers to develop new, attractive and sustainable tourism products (Duman et al., 2020). Consequently, students as hosts have become a prevalent marketing target. As such, the question arises of how students plan activities with their guests and how they perceive their own role as hosts. Additionally, we need to understand the difference for students between hosting friends versus relatives.

In this research, we seek to explore both, the visiting activities of friends and relatives and the roles of students as hosts in the context of city break tourism in Innsbruck, Austria. We thereby address the call of Backer et al. (2020) for more VFR tourism research on the role of hosts carried out outside of Australia, New Zealand, Canada, the UK and the USA. To the authors' best knowledge, this study is the first delivering empirical insights on students hosting friends and relatives (SHFR) in Central Europe.

Backer et al. (2020) highlight that the role of the VFR host centrally defines VFR tourism. In this regard, we understand that the role of students as hosts needs a deeper exploration and empirical insights. In an attempt to shed more light into this research area, we put forward the following research questions:

$R Q 1$. How do hosting activities differ between students hosting friends and students hosting relatives?

RQ2. How do hosting styles differ between students hosting friends and students hosting relatives?

To answer these questions our study is divided into two parts: first we asked students about differences in their hosting regarding the friends and the relatives segment. Second, we asked students about their approach to hosting, independently of hosting either friends or relatives. Results allow us to derive implications for students' importance for the local economy at tourism destinations and to derive destination marketing implications due to the following reasons.

Following Choi and Fu (2018), students are a kind of sojourner with long-term destination experience and are therefore able to share local and tourism information, as well as positive and negative experiences with visitors. Students as hosts often accompany VFR, guiding them to local places outside a destination's main tourism sights and attractions, thereby increasing crowding in some destinations (Griffin, 2013a). Students have university vacations during the peaks of the tourism season in many countries, for example, at Christmas, Easter and in the summer. As a result, VFR tourism generally occurs off-season, stabilizing the local economy and tourism supply (Backer and Lynch, 2017). 
The latter is likely to be of even greater importance in the context of tourism recovery strategies and destination developments in the light of COVID-19. As outlined by the United Nations (2020), the pandemic has created the largest disruption of education systems in history and affected $94 \%$ of the word's student population. Besides the catastrophic social, psychological and economical effects, there are also effects on student mobility. Exchange programs and semesters abroad have come to a halt, whereas distance learning became the new normal. While the pandemic heavily impacts tourism at present, the aforementioned benefits of SHFR might be assets in a destination's resilience strategy.

\section{Theoretical background}

\subsection{Differences between visiting friends and relatives}

One of the greatest differences separating VFR from other travel purposes is that hosts and visitors always have some type of relationship. This unique connection between VFR hosts and travelers adds an inimitable component to VFR (Backer, 2008; Choi and Fu, 2018).

Following Lockyer and Ryan (2007), friends tend to seek adventure and fun, whereas relatives emphasize the family aspects of their trips. In terms of the choice of activities, age plays a more significant role than the VF versus VR distinction. Moreover, hosts' opinions tend to influence which attractions are visited. Similarly, Backer et al. (2017) find significant differences between VF and VR travelers, such that the number of VR travelers exceeds the number of VF travelers; spending time together is essential and "in-home" activities are more frequent for $\mathrm{VR}$, whereas for $\mathrm{VF}$, shared interests and the fun components of trips are essential, leading to more outdoor activities with friends (Yousuf and Backer, 2017). Thus, hosting friends seems more exhilarating and entertaining than hosting relatives, given their common interests and hobbies.

\subsection{Role and types of hosts}

Backer (2008) highlights the central role of the host in the whole tourism system (i.e. tourists, tourist generating regions, transit routes, tourist destination regions and tourism industries). Viewing VFR tourism from an open system perspective (Leiper, 2004) helps to understand how VFR tourists are connected with the destination through their hosts. As such, hosts play key roles, functioning "effectively [...] as gatekeepers with respect to information for the relatives they are hosting" (Backer et al., 2017, p. 62).

The personal relationships between visitors and hosts are influenced by the insider knowledge of the hosts, who determine visitors' travel behaviors. Hosts not only have a clear impact on destination choices and frequency of return visits but they also determine the activities undertaken and the sources of information used during the trips (Choi and Fu, 2018; Griffin, 2013b; Munoz et al., 2017). The local host is often perceived as the local expert with valuable knowledge regarding local rather than touristic attractions and hospitality amenities, such as bars, restaurants, shops and markets (Shani, 2013). Young et al. (2007) assert that VFR hosts become "pull factors," convincing their families and friends to visit. Moreover, they exercise strong word of mouth (WOM) power in advertising and promoting the attractions of their regions.

Yousuf and Backer (2017) describe three core VFR host types using accommodation (host"s home or commercial) and purpose of visit for visitor (VFR or non VFR) as differentiators. Shani and Uriely (2012) offer another typology. They identify four styles of hosting friends and relatives (HFR):

1. focusing on in-home hospitality,

2. serving as a local tourist guide, 


\section{3. becoming a tourist in one's own backyard; and}

4. maintaining the normal course of daily life.

The authors classify hosting according to hosting orientation - that is, whether the hosting is guest-oriented or self-oriented - as well as hosting zone. They note that the behavior of hosts varies according to whether they engage mostly in indoor activities or mostly visit outdoor attractions (Shani and Uriely, 2012).

Choi and Fu (2018) differentiate two groups of hosts: one prepares for visitors by previsiting attractions and places, whereas the other rarely prepare, making first-time visits to places and attractions with their visitors. The authors maintain that the various strategies of hosts are limited by five constraints (time, money, distance, age/life cycle and institutional barriers), as well as by four pull factors (ability to host, active communication, destination offerings and selective information sharing). Backer (2019) examines whether HFR increases or decreases hosts' quality of life. The function of hosting provides great joy and contributes positively to the quality of life of most respondents. Negative aspects are linked to difficulties such as a loss of privacy, added stress, difficulty catering to visitors' dietary requirements, sharing bathrooms or not having enough bedrooms. Not surprisingly, the type of visitor and the length of stay are often mentioned as differentiators of positive and negative experiences.

Moreover, VFR hosts become tourists themselves as they act and spend like tourists (Young et al., 2007). Griffin and Guttentag (2020) analyze them regarding their activity and arrive at a high, medium- and low activity cluster.

\subsection{Students hosting friends and relatives}

The relevance of students being part of the VFR segment has been discussed under various aspects (Gafter and Tchetchik, 2017; Kashiwagi et al., 2018; Michael et al., 2003; Min-En, 2006; Tran, Moore and Shone, 2018; Zhao et al., 2019). Taylor et al. (2004) study the economic contributions and relevance of VFR tourism, focusing on international students in Australia. Bischoff and Koenig-Lewis (2007) explain the role of students in attracting friends and relatives as visitors to their places of study; the most popular activities for VF travelers are going to restaurants, shopping, visiting local attractions and nightclubbing; when they visit, the hosts' expenditure increases.

Liu and Ryan (2011) find that students fulfill a number of roles as guides, sources of information and hosts. With regard to students who engage in VFR tourism as hosts and/or guests, throughout the pre-, current- and post-education periods, Tran et al. (2018) find that many former students return to their study locations during the post-education phase.

\section{Research design}

This research project adopts a multi-method approach to derive a deeper empirical understanding of visitors' behaviors and the role of students hosting friends and relatives. As a result marketing implications for destination marketing organizations (DMOs) that seek to realize the potential of the student VFR segment arise. Both methods address students as hosts of VFR travel in a large university town in Austria. The quantitative study addresses $R Q 1$ and aims to reveal the relevance and differences between VF and VR. The qualitative study addresses $R Q 2$ by elaborating on the findings of the quantitative study and seeks to understand the role and experiences of students as hosts. We thereby address the call for an empirical understanding of different hosting styles (Griffin and Guttentag, 2020) and of social relations embodied in hosting practices (Janta and Christou, 2019). Data were collected in Innsbruck (Austria), a major alpine university town in Europe, with a resident population of 132,000 plus 27,000 university students, including about 13,000 international students (Universität Innsbruck, 2020). Innsbruck is well-known as an alpine sport and 
student city and is a popular year-round tourism destination for people from all around the world.

\section{Quantitative study}

\subsection{Aim, procedure and sample}

We conducted a survey to investigate the differences between these two subsegments of student-generated VFR tourism in the small university town of Innsbruck (Austria). The questionnaire comprised three parts: the first consisted of questions about general visits of friends and family, including an evaluation of the city of Innsbruck; the second part featured specific questions about respondents' most recent visits from friends or relatives; and the third part gathered demographic details. In line with Bischoff and Koenig-Lewis (2007), we asked survey participants (i.e. students) whether any friends or relatives had stayed with them in the past 12 months and, if so, to categorize them either as friends or relatives. Next, we asked detailed questions about the visitors' stays. The main part of the survey listed 10 activities that we adapted from Bischoff and Koenig-Lewis (2007); we asked participants to indicate whether they had visited any of them with friends and/or relatives, using five-point Likert scales ( 1 = "no visit at all," 5 = "visited very frequently"). Finally, we recorded participants' socio-economic data. It was administered only to students who had indicated that friends or relatives had visited them within the past 12 months. We used an online platform to create the survey and gathered data in 2018. In sum, we collected 307 completed questionnaires. The gender distribution of those we surveyed was fairly even: $58 \%$ of the participants were female and $42 \%$ were male. The average age of the surveyed hosts was 23 years; because the survey was aimed at university students, this average age was representative. On average, participants had lived in the city for three years. With regard to hosts' nationalities, $47.6 \%$ came from Austria, followed by $25.1 \%$ from Germany and $22.1 \%$ from Italy.

\subsection{Results}

With regard to the hosts' role as information keepers, $77.1 \%$ of the hosts indicated they very often accompanied friends on activities and $41.4 \%$ indicated they often accompanied relatives on activities. As reported in Table 1, the frequency of the visits was almost evenly distributed across the four seasons, which supports the ability of VFR travel to contribute to a more sustainable form of tourism and to avoid overcrowding.

Additionally, we analyzed whether there are significant differences between activities undertaken with VF and VR. Results of an independent samples T-test show that VR and VF travel differs significantly with regard to dining, cultural programs, events, nightclubbing, skiing and biking (Figure 1).

While dining and cultural activities occur more frequently with relatives, hosts tend to visit events or nightclubs or go biking or skiing with friends. However, we find no significant differences between VF and VR with regard to typical tourist activities such as sightseeing,

\section{Table 1 Profile of VFR travel reported by the host}

\begin{tabular}{lcccc}
$\begin{array}{l}\text { Frequency of visit } \\
(\%) / \text { season }\end{array}$ & $\begin{array}{c}\text { Winter } \\
\text { (December-February) }\end{array}$ & $\begin{array}{c}\text { Spring } \\
\text { (March-May) }\end{array}$ & $\begin{array}{c}\text { Summer } \\
\text { (June-August) }\end{array}$ & $\begin{array}{c}\text { Autumn } \\
\text { (September-October) }\end{array}$ \\
\hline Never & 7.6 & 12.9 & 29.7 & 15.6 \\
1-2 times & 44.3 & 44.9 & 30.1 & 43.1 \\
3-4 times & 28.0 & 24.7 & 18.5 & 22.9 \\
5-6 times & 10.6 & 9.5 & 10.4 & 9.2 \\
More than 7 times & 9.5 & 8.0 & 11.2 & 9.2
\end{tabular}


Figure 1 SHFR activities undertaken with friends and relatives

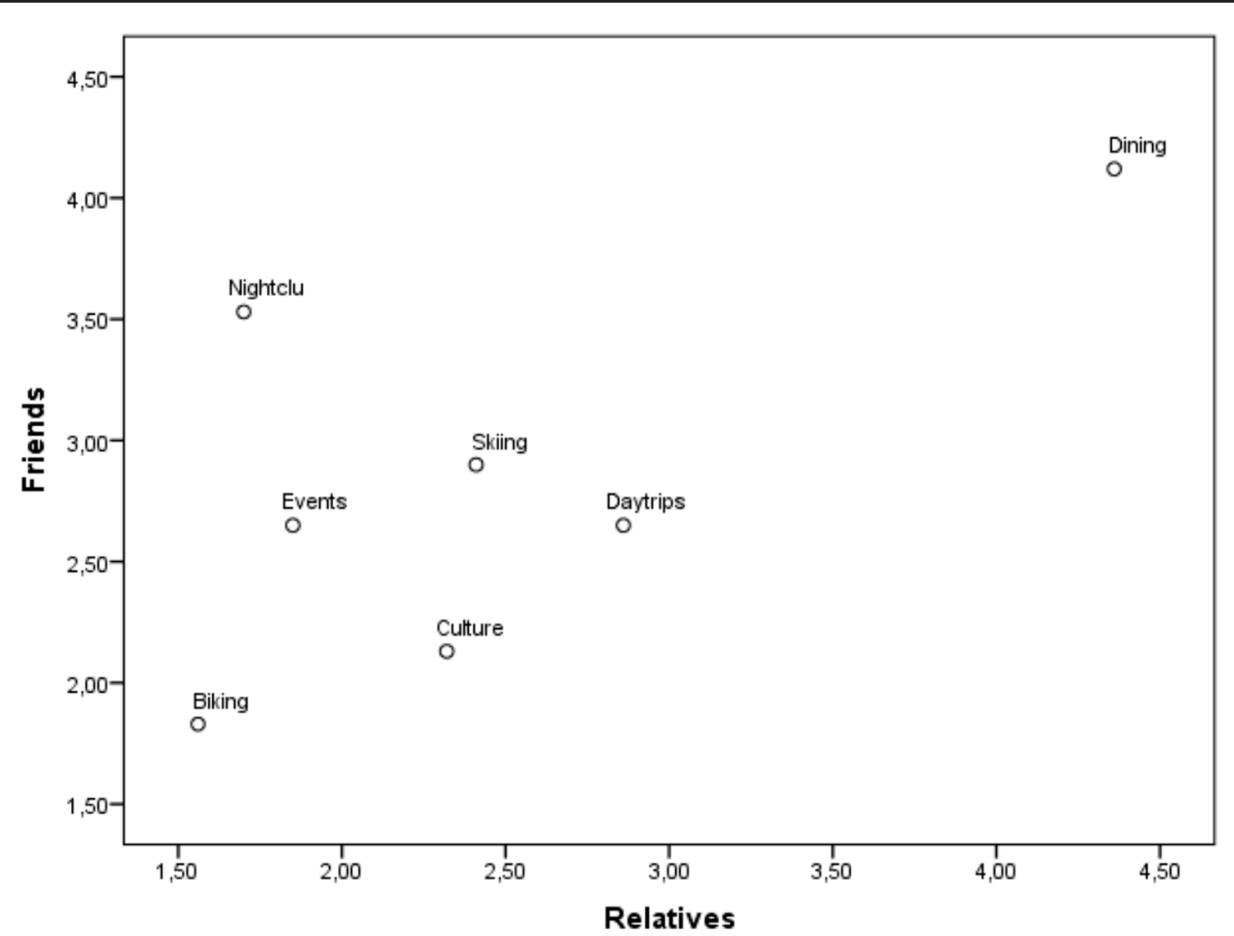

Note: Data points represent mean values of activities done with friends and activities done with relatives as indicated by SHFR on a 7-point Likert scale $(1=$ never; $7=$ very often $)$

shopping, daytrips or hiking. Table 2 provides information about VF and VR travel activities, as provided by hosts.

\subsection{Discussion}

The quantitative study aimed to assess the differences between students hosting friends and students hosting relatives with regard to hosting activities (i.e. RQ1). The results from our quantitative study reveal significant differences in non-typical tourist activities while for typical tourist activities (sightseeing, shopping, daytrips or hiking) there is no significant difference between VF and VR. We conclude that there are specific intra-generational activities of hosts and visiting friends (visiting events, nightclubbing, biking and skiing) and inter-generational activities of hosts and visiting relatives (dining and cultural activities) according to the frequency of these activities. This finding may be explained by generational lifestyles but also by the higher budget of visiting relatives (for dining). Additionally, results show that VFR travel occurs throughout the year which helps tourism marketing to create more sustainable tourism products. These findings underline the relevance of VFR research and support previous literature highlighting the difference between VF and VR travel segments, which calls for distinct marketing activities and forms the foundation for our qualitative study.

\section{Qualitative study}

\subsection{Aim, procedure and sample}

For our qualitative study, we used semi-structured interviews $(n=29)$ to gain a better understanding of the differences between students hosting friends and students hosting 


\begin{tabular}{|c|c|c|c|c|}
\hline \multicolumn{2}{|c|}{ Activity } & \multirow{2}{*}{$\frac{\text { Mean }}{4.12^{*}}$} & \multirow{2}{*}{$\frac{S D}{0.89}$} & \multirow{2}{*}{$\frac{p \text {-value }}{0.00}$} \\
\hline Dining & Friends & & & \\
\hline & Relatives & $4.36^{*}$ & 0.86 & \\
\hline \multirow[t]{2}{*}{ Shopping } & Friends & 3.59 & 1.20 & 0.26 \\
\hline & Relatives & 3.47 & 1.26 & \\
\hline \multirow[t]{2}{*}{ Culture } & Friends & $2.13^{*}$ & 1.02 & 0.04 \\
\hline & Relatives & $2.32^{*}$ & 1.21 & \\
\hline \multirow[t]{2}{*}{ Events } & Friends & $2.65^{*}$ & 1.18 & 0.00 \\
\hline & Relatives & $1.85^{*}$ & 1.07 & \\
\hline \multirow[t]{2}{*}{ Nightclubbing } & Friends & $3.53^{*}$ & 1.22 & 0.00 \\
\hline & Relatives & $1.70^{*}$ & 1.07 & \\
\hline \multirow[t]{2}{*}{ Sightseeing } & Friends & 2.64 & 1.28 & 0.72 \\
\hline & Relatives & 2.68 & 1.29 & \\
\hline \multirow[t]{2}{*}{ Daytrips } & Friends & 2.65 & 1.34 & 0.59 \\
\hline & Relatives & 2.86 & 1.33 & \\
\hline \multirow[t]{2}{*}{ Hiking } & Friends & 2.81 & 1.41 & 0.30 \\
\hline & Relatives & 2.69 & 1.41 & \\
\hline \multirow[t]{2}{*}{ Skiing } & Friends & $2.90^{*}$ & 1.48 & 0.00 \\
\hline & Relatives & $2.41^{*}$ & 1.42 & \\
\hline \multirow[t]{2}{*}{ Biking } & Friends & $1.83^{*}$ & 1.23 & 0.00 \\
\hline & Relatives & $1.56^{*}$ & 1.03 & \\
\hline
\end{tabular}

relatives and to explore the meanings that students attach to their role as hosts. We recruited participants from courses at the Faculty of Business and Management at the University of Innsbruck, Austria in 2018. As in the quantitative study, we selected only students who had been visited by friends and relatives at least once in the past year. Interviews ranged from 19 to $25 \mathrm{~min}$ in length and were consensually recorded before being transcribed verbatim. The topics covered in the interviews included description of visitors and their stays, perceived motives for VFR and for hosting, information about the destination, activities and costs, perceived quality of life at the destinations and areas for improvement. We used the software package Atlas.ti for qualitative and template analysis (King, 2012). Template analysis is a method of thematic analysis that deductively and inductively develops a hierarchical coding template. We designed the initial template using a priori themes from previous VFR studies (Bischoff and Koenig-Lewis, 2007; King, 2012; Shani and Uriely, 2012; Young et al., 2007), applied to five transcripts. Through inductive modification of the initial template in several rounds of coding, the subset of transcripts and team discussions, we constructed the final template and applied it to the entire set of transcripts. Our qualitative sample consisted of nine female and nine male participants, with a mean age of 24 years and a mean length of residence in the town of 2.5 years.

\subsection{Results}

5.2.1 Visiting friends and relatives purpose. Our results show that the vast majority of participant hosts perceive the main purpose of their guests' visits to be VFR. The purpose of VFR has three submotives, expressed with varying levels of affective quality: sense of longing, keeping in touch and curiosity. Only in rare cases do hosts perceive guests to be seeking accommodation only.

Only two participants in our qualitative sample mention sightseeing as a reason for VR, making it too insignificant to have its own category. Participants' suggested reasons for visiting remain rather general, referring to states of being such as being with family and friends or being in the city or the mountains. 
Sense of longing: The closer the relationships between hosts and visitors, the more emotional the VFR purpose and the more detached it is from other reasons for visiting. Elias, for example, assumes that his mother "just comes around, because she misses me." The motive for Jan's friends is "well, longing, I don't go home that much, so they come here."

Keeping in touch: In contrast to longing, this submotive is framed less emotionally; it stresses the relevance of the moment and emphasizes joint activities. Participants often mention this purpose along with other non-VFR reasons for visiting, such as enjoying city life, taking part in events, enjoying natural areas and engaging in outdoor sports, primarily hiking and skiing. The various combinations of reasons mentioned by participants reflect their origins:

Within the region I come from, it is very rare that one lives close to the mountains. This is because the possibilities Innsbruck offers, hiking in summer and skiing in winter are of course a very, very good reason to visit me. (Lena from Germany)

Curiosity: guests are also interested in observing their hosts' personal development and experiencing their new lives during their transition to adulthood. Lisa suggests, "For my parents, the reasons are more that they want to see how you live and what you do." Our interviews reveal that this kind of curiosity shown by significant others is a third sub-motive of VFR travel.

5.2.2 Hosting styles. Our interviews also show that participants interpret their role as hosts in two ways and thus display two styles of hosting. Hosts in the first group see their role in functional terms, stressing its organizational aspects. The central theme of functional hosting is "offering":

Being a host means to be friendly, to offer a lot. For me, hospitality means that there is food on the table as well. Or in the fridge at least. And well, that you are spending a good time together in a family way. (Julia)

Functional hosts find it easier to accept and even enjoy being tourist guides and sometimes become tourists in their city, too. As a resident of Innsbruck for three years, Michaela reflects, "At first I thought Innsbruck to be a small city with limited attractions [...] but over the years I became a little tourist guide and I can say the city has more to offer than I thought."

Often, functionally oriented participants acknowledge the effort and stress associated with this role. Stefan sets the boundaries of his role when "offering a nice stay" turns into serving, and he remarks that his guests "need to cooperate because I cannot do everything by myself."

The second type of host views this role as integrative. The aim is to introduce guests to their own lifestyle and portray their cities from their personal point of view as residents. The central theme of integrative hosts is "sharing is caring." Participants of this type do not normally identify with being tourist guides, because they want to provide a more local and authentic experience. "I want to show my family and friends Innsbruck how I experience it, not following any of the tourist trails, which I personally often think are not authentic," explains Sandra.

5.2.3 Host involvement and place attachment. Usually, the hosts propose the activities, performing a gatekeeping function. They use three decision-making strategies. According to the first strategy, the most informed person plans and chooses the program. For example, as the resident familiar with Innsbruck, Eva makes the decisions for her guests. Hosts tend to be in charge of outdoor activities in particular. Fabian reports, "I don't really plan city activities, you just go and find something, but for going to the mountains, I do plan." The second strategy seeks to include guests in decision-making. For example, Jan's guests "can choose" from the proposals he makes. Finally, the third strategy is to plan ad 
hoc and decide together when the guests arrive. Lorenz seeks to "do everything spontaneously with my friends, no planning in advance, except when there is an event, then you ask whether they are interested or not."

Our interviews reveal that neither guests nor hosts seem to have an in-depth knowledge of Innsbruck's tourist attractions. Lisa explains that proposals need to come from her, "because the [guests] actually don't know much, they know Innsbruck is beautiful and then they just come, but I never had someone here who knew more than one thing you could do."

Hosts in our qualitative study take it for granted they will join their guests in activities and most spend entire visits with their guests. Participants report that they enjoy socializing, but they also want to ensure authentic experiences for their guests:

Well, I always go with them. Simply because then I am able to tell them something and to show them the personal side of the city, not only the tourist attractions. Lately, I find myself avoiding the old town, because there is an old town in almost every city and here it is always very crowded. I believe what they really appreciate are the corners where I use to go. (Katharina)

Place attachment influences hosts' involvement and engagement in WOM as Elias exemplifies the link between place involvement and host involvement: "I enjoy setting up a tour for the guests and then showing them all you have here or why you like this place so much." The interviewees frequently and quite emotionally express their attachment to Innsbruck; some indicate a bittersweet awareness that their stay is limited to their studies and that many of them are merely sojourners.

Place attachment is a main motivator for attracting VFR travelers to Innsbruck. Lisa points out, "I do a lot of marketing for Innsbruck because I tell many people how awesome it is here and I always tell them, 'Hey, if you like, just come visiting.'" As a VFR host, place attachment motivates Fabian to show his guests around, "because I am a bit proud of where I am and of all you can do here and because I think it is super cool here, that's why I want to show it to them."

5.2.4 Costs and constraints. The economic costs for student hosts depend on the type of visitor, that is, whether they are friends or family. In general, hosting friends is more expensive than hosting family:

When friends visit, well, I need more money, that's for sure, because, well, you go eating out in restaurants, you go out at night, you go shopping, you do activities which you normally don't do, you just need more money. When relatives or my parents visit, I actually don't need any money, because they pay for everything. (Sophia)

The participants mention three factors that influence the relative increase in cost when hosting friends compared with everyday life. The first is the student status of friends. The second factor relates to personal lifestyle, in terms of dining out and events. Christian's expenses for dining out, for example, do not increase when he hosts, "because I am a person, who eats out a lot [...] and it is difficult for me to top that." The third factor is the mood of the hosts when they have visitors. Katharina reflects that she "spends much more, because for me it feels a bit like holidays and you don't want to deny yourself nice things then." With regard to the economic costs or benefits of hosting family, participants report that though the types of activities they engage in are the same for both groups, activities with family are more premium and thus more costly.

\subsection{Discussion}

The aim of our qualitative study was to gain a nuanced understanding of students as hosts, in particular regarding differences in their hosting styles for friends and relatives (i.e. RQ2) in the context of VFR travel to tourist cities and to explore their relevance as targets for destination marketing organizations, as well as their contribution to community. 
These results indicate that differences between VF and VR relate more to visitors' travel budgets than to their status as friends or relatives. The results from our interviews reveal that students largely associate positive experiences with hosting friends and relatives despite constraints due to budget or confined living accommodation. They underline the social purposes of the visits and express a profound sense of pride in being an able host for their significant others and in living and studying in an attractive destination.

Our findings further reveal that VR and VF travelers vary in terms of their expenditure. Hosts' spending depends on visitors' budgets; in general, both their direct and indirect (when relatives pay) spending increases when they have visitors. Hosts indicate that the VF experience is more costly than the VR experience because VR travelers frequently pay for dinner and other expenses. Moreover, there are differences within the VF segment with regard to student status: Student VF travelers keep their budgets low. However, when VF travelers are used, visits become more costly.

From our data, we can identify two distinct hosting styles relating to the interpretations of the role as host. Functional hosting is concerned with providing outstanding hospitality based on a more traditional, guest-oriented understanding of the role, whereas integrative hosting blurs the lines between hospitality and lifestyle based on a more modern, host-oriented understanding of the role.

\section{Discussion and implications}

This research aimed at investigating the difference for students between hosting friends versus relatives, how they experience and perceive their own role as hosts and how they plan activities with their guests. In line with Griffin and Guttentag (2020), our results show that SHFR is a multidimensional phenomenon, characterized by the type of guests, the hosting style, high levels of both outdoor and indoor host involvement and seasonality (due to the summer break).

Our key finding is that students as hosts want to provide particularly authentic city impressions. Thus, it is not surprising that mainstream tourist attractions are not a priority for most hosts and visitors. Our results reveal significant differences between VF and VR in non-typical tourist activities while for typical tourist activities (sightseeing, shopping, daytrips or hiking) there is no significant difference between VF and VR. Hosts are the drivers of planning activities, as guests are usually rather unprepared. As such, they hold an important gatekeeper-function in terms of marketing information for DMOs.

The results of this study are therefore also of practical value for tourism marketing organizations. Students as hosts differ from other hosts in VFR travel in their reluctance to embrace conventional tourism products. This finding is of particular relevance because the COVID-19 pandemic is forcing DMOs to develop strategies that incorporate socialdistancing and avoid crowded places. In this regard, the findings are in line with Backer and Ritchie (2017), suggesting that VFR travel can be an appropriate target segment for destinations after a crisis.

Considering the finding that students as hosts co-create experiences with VFR travelers, DMOs should strive to make hosts familiar with alternative products and services that meet their demands. Activities often take place in the hidden corners, rather than on the welltrodden paths of the city. This insight offers DMOs the opportunity to advertise alternative sights, beyond the main attractions, to the VFR segment, thus allowing local stakeholders such as bars, clubs and restaurants to benefit from the value these visitors create. At the same time, it is a chance to exploit existing experiences for the new market of studentbased VFR travel (Gardiner and Scott, 2018), such as promoting "hip" cafés and kitchens or cultural events. 
Dining out is the activity that students as hosts most frequently share with friends and relatives. Accordingly, DMOs could offer students vouchers for restaurants and bars when they register friends and relatives online. The vouchers might include not only restaurants in the tourist center but also in less-frequented areas of the city, to move crowds away from the tourist centers and introduce additional restaurants (i.e. stakeholders) into the tourism value chain. Such activities would also contribute to a sustainable destination development strategy. Another option for sustainable destination development is to market to VFR travelers during the off-season, such that they receive special offers for VFR travel during less busy times of the year. Such promotions would limit city-center congestion and help foster year-round employment, which will be a key issue for destination recovery.

We found that place attachment makes hosts of VFR travelers passionate ambassadors and advertisers for the destinations; DMOs could support this already positive image by providing students with more detailed information about their cities and the opportunities they offer. When students take their friends out to events and nightclubs, they contribute significantly to experiences that go beyond typical tourism activities such as sightseeing and shopping.

Finally, though DMOs always strive to collect data about their visitors, collecting data on VFR travel is difficult because VF and VR travelers frequently stay at hosts' residences. Therefore, DMOs could offer websites and social media channels for students that inform them about alternative activities they can undertake with friends and relatives beyond the traditional tourist hotspots.

\section{Limitations}

As with all research, our research bears limitations, which open-up avenues for further research. First, our study takes place in a specific context, that is, students in Innsbruck, Austria. We did not differentiate between students who were simultaneously locals and students who resided in the city only for study purposes. Further research should thus differentiate between such student segments to gain an even deeper understanding of the SHFR segments. In a similar vein, the cultural background of the students was not considered in our research, which needs to be addressed in further research by taking a cross-cultural perspective. Finally, the differences between VF and VR could further be explored in a quantitative follow-up study and in testing for significant differences in SHFR spending behaviors.

Given that the data from our two studies were gathered before COVID-19, further research should examine whether domestic travelers, travelers with cultural proximity and/or shortdistance VFR travelers are more likely to visit after COVID-19 as suggested by Backer and Ritchie (2017) in the case of crises and disaster. Additionally, a follow-up study should assess whether students hosting friends and family perceive their role as hosts as being different after lockdown as compared to before.

\section{Acknowledgment}

This research was funded by OeAD-GmbH project EPU 45/2018.

\section{References}

Backer, E. (2008), "VFR travellers-visiting the destination or visiting the hosts", Asian Journal of Tourism and Hospitality Research, Vol. 2 No. 1, pp. 60-70.

Backer, E. (2019), "VFR travel: do visits improve or reduce our quality of life?", Journal of Hospitality and Tourism Management, Vol. 38 No. 1, pp. 161-167. 
Backer, E. and Lynch, D. (2017), "Understanding the proclivity of visiting friends and relatives (VFR) travel across family life cycle stages in Australia", International Journal of Tourism Research, Vol. 19 No. 4, pp. 447-454.

Backer, E. and Ritchie, B. (2017), "VFR travel: a viable market for tourism crisis and disaster recovery?", International Journal of Tourism Research, Vol. 19 No. 4, pp. 400-411.

Backer, E., Leisch, F. and Dolnicar, S. (2017), "Visiting friends or relatives? ", Tourism Management, Vol. 60 No. 1, pp. 56-64.

Backer, E., Erol, G. and Düşmezkalender, E. (2020), "VFR travel interactions through the lens of the host", Journal of Vacation Marketing, Vol. 26 No. 4, pp. 1-15. (online first)

Bischoff, E. and Koenig-Lewis, N. (2007), "VFR tourism: the importance of university students as hosts", International Journal of Tourism Research, Vol. 9 No. 6, pp. 465-484.

Choi, S.-H. and Fu, X. (2018), "Hosting friends and family as a sojourner in a tourism destination", Tourism Management, Vol. 67 No. 1, pp. 47-58.

Duman, T., Erkaya, Y. and Topaloglu, O. (2020), "Vacation interests and vacation type preferences in Austrian domestic tourism", Journal of Travel \& Tourism Marketing, Vol. 37 No. 2, pp. 217-245.

Gafter, L.M. and Tchetchik, A. (2017), "The role of social ties and communication technologies in visiting friends tourism - a GMM simultaneous equations approach", Tourism Management, Vol. 61, pp. 343-353.

Gardiner, S. and Scott, N. (2018), "Destination innovation matrix: a framework for new tourism experience and market development", Journal of Destination Marketing \& Management, Vol. 10, pp. 122-131.

Griffin, T. (2013a), "Visiting friends and relatives tourism and implications for community capital", Journal of Policy Research in Tourism, Leisure and Events, Vol. 5 No. 3, pp. 233-251.

Griffin, T. (2013b), "Research note: a content analysis of articles on visiting friends and relatives tourism, 1990-2010", Journal of Hospitality Marketing \& Management, Vol. 22 No. 7, pp. 781-790.

Griffin, T. and Guttentag, D. (2020), "Identifying active resident hosts of VFR visitors", International Journal of Tourism Research, Vol. 22 No. 5, pp. 1-20. (online first)

Janta, H. and Christou, A. (2019), "Hosting as social practice: gendered insights into contemporary tourism mobilities", Annals of Tourism Research, Vol. 74, pp. 167-176.

Kashiwagi, S., Nagai, H. and Furutani, T. (2018), "VFR travel generated by international students: the case of Japanese students in Australia", Turizam: Međunarodni Znanstveno-Stručni Časopis, Vol. 66 No. 1, pp. 89-103.

King, N. (2012), "Doing template analysis", in Symon, G. and Cassell, C. (Eds), Qualitative Organizational Research: Core Methods and Current Challenges, Sage, Los Angeles, CA, pp. 426-440.

Leiper, N. (2004), Tourism Management, 3rd ed., Pearson, Australia.

Liu, G. and Ryan, C. (2011), "The role of Chinese students as tourists and hosts for overseas travel", Asia Pacific Journal of Tourism Research, Vol. 16 No. 4, pp. 445-464.

Lockyer, T. and Ryan, C. (2007), "Visiting friends and relatives - distinguishing between the two groups: the case of Hamilton, New Zealand", Tourism Recreation Research, Vol. 32 No. 1, pp. 59-68.

Michael, I., Armstrong, A. and King, B. (2003), "The travel behaviour of international students: the relationship between studying abroad and their choice of tourist destinations", Journal of Vacation Marketing, Vol. 10 No. 1, pp. 57-66.

Min-En, A.T. (2006), "Travel stimulated by international students in Australia", International Journal of Tourism Research, Vol. 8 No. 6, pp. 451-468.

Munoz, J.R., Griffin, T. and Humbracht, M. (2017), "Towards a new definition for 'visiting friends and relatives", International Journal of Tourism Research, Vol. 19 No. 5, pp. 477-485.

Shani, A. (2013), “The VFR experience: 'home' away from home?", Current Issues in Tourism, Vol. 16 No. 1, pp. 1-15.

Shani, A. and Uriely, N. (2012), "VFR tourism", Annals of Tourism Research, Vol. 39 No. 1, pp. 421-440.

Taylor, R., Shanka, T. and Pope, J. (2004), "Investigating the significance of VFR visits to international students", Journal of Marketing for Higher Education, Vol. 14 No. 1, pp. 61-77. 
Tran, M.N.D., Moore, K. and Shone, M.C. (2018), "Interactive mobilities: conceptualising VFR tourism of international students", Journal of Hospitality and Tourism Management, Vol. 35 No. 1, pp. 85-91.

United Nations (2020), "Policy brief: education during COVID-19 and beyond", available at: www.un.org/ development/desa/dspd/wp-content/uploads/sites/22/2020/08/sg_policy_brief_covid-19_and_education_ august_2020.pdf (accessed 30 November 2020).

Universität Innsbruck (2020), "Uni in Zahlen - Auf einen Blick 2019", available at: www.uibk.ac.at/ universitaet/profil/dokumente/uni-in-zahlen-2019.pdf (online 27 May).

Young, C.A., Corsun, D.L. and Baloglu, S. (2007), "A taxonomy of hosts visiting friends and relatives", Annals of Tourism Research, Vol. 34 No. 2, pp. 497-516.

Yousuf, M.S. and Backer, E. (2017), "Hosting friends versus hosting relatives: is blood thicker than water?", International Journal of Tourism Research, Vol. 19 No. 4, pp. 435-446.

Zhao, Y., Chen, F. and Xu, H. (2019), "It is a way of life": detecting Chinese students' wellbeing during the spring festival homecoming", Journal of Travel \& Tourism Marketing, Vol. 37 No. 5, pp. 1-15.

\section{Corresponding author}

Birgit Pikkemaat can be contacted at: Birgit.Pikkemaat@uibk.ac.at

For instructions on how to order reprints of this article, please visit our website: www.emeraldgrouppublishing.com/licensing/reprints.htm

Or contact us for further details: permissions@emeraldinsight.com 